OPEN ACCESS

Edited by:

Barak Bar,

Loyola University Medical Center,

USA

Reviewed by:

Ahmed Hassan,

University of Illinois at Chicago,

USA

Ryan Matthew Martin, University of California Davis, USA

*Correspondence:

Marc-Alain Babi ncc.babi@gmail.com

Specialty section: This article was submitted to

Neurocritical and Neurohospitalist Care, a section of the journal

Frontiers in Neurology

Received: 23 September 2016 Accepted: 04 January 2017

Published: 19 January 2017

Citation:

Babi M-A and James ML (2017)

Peri-Hemorrhagic Edema and Secondary Hematoma Expansion after Intracerebral Hemorrhage:

From Benchwork to

Practical Aspects.

Front. Neurol. 8:4.

doi: 10.3389/fneur.2017.00004

\section{Peri-Hemorrhagic Edema and Secondary Hematoma Expansion after Intracerebral Hemorrhage: From Benchwork to Practical Aspects}

\author{
Marc-Alain Babi' ${ }^{*}$ and Michael L. James ${ }^{1,2}$ \\ ${ }^{1}$ Division of Neuro-Critical Care, Department of Neurology, Duke University, Durham, NC, USA, ${ }^{2}$ Division of Neurosurgical \\ Anesthesia, Department of Anesthesiology, Duke University, Durham, NC, USA
}

Spontaneous intracerebral hemorrhage $(\mathrm{SICH})$ is the most lethal type of stroke. Half of these deaths occur within the acute phase. Frequently observed deterioration during the acute phase is often due to rebleeding or peri-hematomal expansion. The exact pathogenesis that leads to rebleeding or peri-hemorrhagic edema remains under much controversy. Numerous trials have investigated potential predictor of peri-hemorrhagic edema formation or rebleeding but have yet to come with consistent results. Unfortunately, almost all of the "classical" approaches have failed to show a significant impact in regard of significant clinical outcome in randomized clinical trials. Current treatment strategies may remain "double-edged swords," for inherent reasons to the pathophysiology of sICH. Therefore, the right balance and possibly the combination of current accepted strategies as well as the evaluation of future approaches seem urgent. This article reviews the role of disturbed autoregulation following $\mathrm{SICH}$, surgical and non-surgical approaches in management of $\mathrm{SICH}$, peri-hematoma edema, peri-hematoma expansion, and future therapeutic trends.

Keywords: ICH, intracerebral hemorrhage, brain injury, cerebral edema, intracranial pressure

\section{INTRODUCTION}

Spontaneous intracerebral hemorrhage (sICH) accounts for approximately $13-17 \%$ of all strokes; however, sICH carries substantial mortality and morbidity, approaching approximately $50 \%$ within 3 months and severe disability in the majority of survivors. Half of these deaths occur within the acute phase (1). Neurological deterioration during the acute phase may be due to hematoma expansion or peri-hemorrhagic edema growth (2). Since hematoma growth tends to occur within the first $24 \mathrm{~h}$ and edema formation within the first $72 \mathrm{~h}$ from symptoms onset, intervention during this time period may modify long-term outcome (2). Thus, the dynamic nature of early sICH represents a management challenge and opportunity for intervention. In this review, we discuss the pathogenesis and the role of different proposed pathways that have been explored to contribute to sICH progression. 


\section{PATHOGENESIS}

\section{Biology}

The pathophysiology leading to hematoma expansion and edema progression remains poorly understood. $\mathrm{sICH}$ is believed to result from rupture of lipohyalinoic arteries followed by secondary arterial rupture at the periphery of the enlarging hematoma, in an "avalanche" fashion (2). This model was first proposed by C. Miller Fisher in the early 1970s $(2,3)$. Hematoma expansion may reflect additional leakage, extended spatial distribution of the initial hemorrhage, or both. Based on this model, mechanical disruption may be considered the most important neuropathological correlate for the expanding hematoma (2). Hematoma expansion leads to secondary injury mechanisms, which accentuates tissue destruction. Yet, exact pathophysiological mechanisms are unclear.

Prediction of risk factors for hematoma expansion and subsequent secondary injury might provide a first step toward development of effective therapies. Hematoma expansion and edema generation do not appear related to a single mechanistic pathway or risk factor, but rather several pathways/factors thought to act in synergy. Early preclinical models proposed the concept of "peri-hemorrhagic ischemia" surrounding the primary hematoma $(2,4-7)$. However, subsequent metabolism and flow studies demonstrated that such peri-hematoma changes were far from universal (7-10). Perihematomal changes lead to cytotoxic edema and neuroinflammatory mediators $(11,12)$.

\section{Role of Disturbed Inflammation}

Numerous human and preclinical studies suggest a link between inflammation, peri-hematoma edema formation, and hematoma expansion. These studies particularly shed light on a direct role of neutrophil activation, free-radical formation, and the expression of interleukin-6 (IL-6) and tumor-necrosis alpha (TNF- $\alpha$ ) (13-15). Several rat model studies have also shown that formation of the peri-hemorrhagic penumbra can be mediated by various neuroprotective elements such as $N$-methyl-D-aspartate receptor antagonism. The latter blunts excitatory amino acid-mediated neuronal death and diminishes microglia-mediated neuronal injury $(11,12,16)$. Studies have also linked elevated plasma concentration of cellular fibronectin (c-FN) and inflammatory mediators IL- 6 and TNF- $\alpha$ in the early phase of hematoma enlargement (13-15). However, the clinical utility of matrix metalloproteinase (MMP), c-FN, TNF- $\alpha$, or IL- 6 blood concentrations in early ICH remains unclear. Another distinct pathway that supports the role of neuro-inflammation in hematoma expansion includes thrombin-induced activation of inflammatory cascade; the latter being an important regulator of cellular activation through binding to the protease-activated receptors (PARs) expressed on platelets, leukocytes, and endothelial cells (ECs) (17-20), along overexpression of MMP (17-19). The latter promotes extracellular matrix proteolysis, attack the basal lamina, and results in degradation of c-Fn $(17-19,21)$. The expression of such inflammatory processes seem to coincide chronologically with the peak of peri-hemorrhagic edema formation and secondary hematoma expansion; when its maximal potential is often reached by $3-5$ days from the initial ictus of hematoma formation $(2,10,22,23)$.

\section{Role of Disturbed Autoregulation}

Disturbed autoregulation and uncontrolled perfusion pressure in hypertension may act as a driving force for hematoma expansion and peri-hemorrhagic edema formation. Numerous studies have suggested that blood pressure elevation may worsen ICH by providing continued force for hematoma expansion and potentially worsening outcomes $(24,25)$. However, aggressively blood pressure lowering after sICH may be counterintuitive. Elevation in mean arterial pressure may be a natural response to preserve cerebral perfusion. Qureshi et al. (26) describe three distinct phases of metabolic changes with respect to autoregulation: hibernation, seen during the first $48 \mathrm{~h}$ with reduction of $\mathrm{CBF}$, and metabolism occurring in bilateral cerebral hemispheres; reperfusion, which may last up to 14 days with heterogeneous areas of cerebral hypo- and hyperperfusion; and finally, normalization, with resolution and development of normal cerebral flow pattern except in non-viable brain tissue (3, 26-32). Numerous models demonstrated that acute blood pressure reduction is associated with decreased diffusion on brain imaging $(21,33)$. However, studies have found no clear clinical implication of these findings $(34,35)$. Major randomized clinical trials (ATACH, INTERACT, and INTERACT-2) have explored the relationship of blood pressure reduction and clinical outcomes in ICH. While no sustained long term outcome benefit has been found for aggressive blood pressure management, interventions do appear to be safe (36-38). More recently, the ATACH 2 trial further re-affirmed that intense BP control (target 110-139 $\mathrm{mmHg}$ ) did not result in an incremental benefit or lower rate of death or disability than standard reduction to a target of $140-179 \mathrm{mmHg}(21,33-35,39)$.

\section{Role of Hemostasis}

While homeostatic therapies seem promising, through prevention of hematoma enlargement, clinical trials examining use of blood products (in particular recombinant factor VIIa) remains inconclusive. While initial preliminary data suggested that Factor VIIa may be safe $(40,41)$, results from a phase- 3 randomized controlled trial showed that although recombinant factor VIIa use after ICH resulted in significant reduction in hematoma volume but no reduction in severe disability or death compared to placebo at 3 months (42). If fact, recombinant factor VIIa use after ICH was associated with higher risk of arterial thromboembolic adverse events (43). The current AHA/ASA guidelines have since concluded that recombinant factor VIIa remains investigational and should not be used in sICH (44). While there is no disagreement in regard of coagulopathy reversal for patients' who develop acute intracerebral hemorrhage while on anticoagulant therapy, the role of platelet transfusion remains controversial. A recent multicenter randomized controlled trial suggested (PATCH) suggested that platelet transfusion is inferior to standard of care for patients who develop intracerebral hemorrhage while on antiplatelet therapies, and thus cannot be recommended (45). 


\section{Surgical Hematoma Evacuation}

Surgical evacuation of the hematoma, and on whether this is beneficial, remains under investigation. Under select circumstances, various surgical approaches may be undertaken. This may include conventional craniotomy, stereotactic guidance with aspiration and thrombolysis, image-guided stereotactic endoscopic aspiration, and decompressive craniectomy. The overall aim of surgical intervention is to remove the source of hemorrhage, eliminate the localized or global mass effect of the hematoma, and eliminate the toxic effects of blood degradation products. To date, two major randomized controlled trials (STITCH I and STICH-II) explored surgical vs non-surgical management of $\mathrm{ICH}(46,47)$. However, those trials failed to show an outcome benefit over conservative treatment. However, one of the largest meta-analysis which also included the STICH-II data suggested an overall benefit for surgery for select subgroups of patients, including those with poorer prognosis at presentation, those with secondary deterioration attributed to hematoma expansion, and those with superficial ICH without intraventricular extension (48).

Recently, minimally invasive and stereotactic surgeries have emerged as an alternative to craniotomy for hematoma evacuation. The more recently published ICES (intraoperative stereotactic computed tomography-guided endoscopic surgery) study suggested that early computerized tomographic image-guided endoscopic surgery is a safe and effective method in select cases to remove acute intracerebral hematomas, with a potential to enhance neurological recovery (49). Similarly, the MISTIE trial (minimally invasive surgery plus alteplase) in intracerebral hemorrhage evacuation appeared overall safe and promising in $\mathrm{ICH}$

\section{REFERENCES}

1. Sacco S, Marini C, Toni D, Olivieri L, Carolei A. Incidence and 10 year survival of intracerebral hemorrhage in a population-based registry. Stroke (2009) 40:394-9. doi:10.1161/STROKEAHA.108.523209

2. Kase CS, Mohr JP, Caplan LR, editors. Intracerebral hemorrhage. Stroke: Pathophysiology, Diagnosis and Management. 4th ed. Philadelphia: Churchill Livingstone (2004). p. 30-65.

3. Qureshi AI, Wilson DA, Hanley DF, Traystman RJ. No evidence for an ischemic penumbra in massive experimental intracerebral hemorrhage. Neurology (1999) 52(20):266-72. doi:10.1212/WNL.52.2.266

4. Sinar EJ, Mendelow AD, Graham DI, Teasdale GM. Experimental intracerebral hemorrhage: effects of a temporary mass lesion. J Neurosurg (1987) 66(4):568-76. doi:10.3171/jns.1987.66.4.0568

5. Bullock R, Brock-Utne K, van Dellen J, Blake G. Intracerebral hemorrhage in a primate model: effect on regional cerebral blood flow. Surg Neurol (1988) 29(2):101-7. doi:10.1016/0090-3019(88)90065-1

6. Nehls DG, Mendelow AD, Graham DI, Sinar EJ, Teasdale GM. Experimental intracerebral hemorrhage: progression of hemodynamic changes after production of a spontaneous mass lesion. Neurosurgery (1988) 23(40):439-44. doi:10.1097/00006123-198810000-00006

7. Yang GY, Betz AL, Chenevert TL, Brunberg JA, Hoff JT. Experimental intracerebral hemorrhage: relationship between brain edema, blood flow, and blood-brain barrier permeability in rats. J Neurosurg (1994) 81(1):93-102. doi:10.3171/jns.1994.81.1.0093

8. Mayer SA, Lignelli A, Fink ME, Kessler DB, Thomas CE, Swarup R, et al. Perilesional blood flow and edema formation in acute intracerebral hemorrhage: a SPECT study. Stroke (1998) 29(9):1791-8. doi:10.1161/ 01.STR.29.9.1791
(50). However, many questions remain regarding the surgical optimization of the endoscopic technique, the patients' selection, and the timing of surgery. The role of minimally and endoscopic surgery will continue to evolve as more centers continue to gain experience with this promising approach.

\section{CONCLUSION}

Current treatment strategies may remain "double-edged swords." For example; surgical intervention may reduce hematoma volume but may also lead to decompression of the surrounding "peri-hemorrhagic penumbra tissue" with subsequent re-accumulation of bleeding. Likewise, hemostasis might stop cerebral bleeding yet compromise normal circulation. Blood pressure reduction decreases hematoma expansion but may also decrease cerebral perfusion and other vital organ blood flow. Therefore, balance of current accepted strategies and the evaluation of future approaches seem critical. This topic will continue to evolve as our understanding of the pathogenesis of sICH and secondary hematoma expansion continue to evolve.

\section{AUTHOR CONTRIBUTIONS}

$\mathrm{M}-\mathrm{AB}$ and $\mathrm{MJ}$ contributed to the preparation and drafting of this manuscript. All authors have read and approved this manuscript in its final form.

\section{FUNDING}

$\mathrm{M}-\mathrm{AB}$ and $\mathrm{MJ}$ have no grants to declare.

9. Zazulia AR, Diringer MN, Videen TO, Adams RE, Yundt K, Aiyagari $\mathrm{V}$, et al. Hypoperfusion without ischemia surrounding acute intracerebral hemorrhage. JCereb Blood Flow Metab (2001) 21(7):804-10. doi:10.1097/00004647-200107000-00005

10. Carhuapoma JR, Wang PY, Beauchamp NJ, Keyl PM, Hanley DF, Barker PB. Diffusion-weighted MRI and proton MR spectroscopic imaging in the study of secondary neuronal injury after intracerebral hemorrhage. Stroke (2000) 31(3):726-32. doi:10.1161/01.STR.31.3.726

11. Mendelow AD. Mechanisms of ischemic brain damage with intracerebral hemorrhage. Stroke (1993) 24:I115-7; discussion I118-9.

12. Oeinck M, Neunhoeffer F, Buttler KJ, Meckel S, Schmidt B, Czosnyka M, et al. Dynamic cerebral autoregulation in acute intracerebral hemorrhage. Stroke (2013) 44:2722. doi:10.1161/STROKEAHA.113.001913

13. Silva Y, Leira R, Tejada J, Lainez JM, Castillo J, Dávalos A, et al. Molecular signatures of vascular injury are associated with early growth of intracerebral hemorrhage. Stroke (2005) 36:86. doi:10.1161/01.STR.0000149615. $51204.0 \mathrm{~b}$

14. Florczak-Rzepka M, Grond-Ginsbach C, Montaner J, Steiner T. Matrix metalloproteinases in human spontaneous intracerebral hemorrhage - an update. Cerebrovasc Dis (2012) 34:249-62. doi:10.1159/000341686

15. Alvarez-Sabín J, Delgado P, Abilleira S, Molina CA, Arenillas J, Ribó M, et al. Temporal profile of matrix metalloproteinases and their inhibitors after spontaneous intracerebral hemorrhage: relationship to clinical and radiological outcome. Stroke (2004) 35:1316-22. doi:10.1161/01.STR.0000126827. 69286.90

16. Lee KR, Kawai N, Kim S, Sagher O, Hoff JT. Mechanisms of edema formation after intracerebral hemorrhage: effects of thrombin on cerebral blood flow, blood-brain barrier permeability, and cell survival in a rat model. J Neurosurg (1997) 86:272. doi:10.3171/jns.1997.86.2.0272 
17. Rosenberg GA, Navratil M. Metalloproteinase inhibition blocks edema in intracerebral hemorrhage in the rat. Neurology (1997) 48:921. doi:10.1212/ WNL.48.4.921

18. Xi G, Wagner KR, Keep RF, Hua Y, de Courten-Myers GM, Broderick JP, et al. Role of blood clot formation on early edema development after experimental intracerebral hemorrhage. Stroke (1998) 29:2580. doi:10.1161/01. STR.29.12.2580

19. Makogonenko E, Tsurupa G, Ingham K, Medved L. Interaction of fibrin(ogen) with fibronectin: further characterization and localization of the fibronectinbinding site. Biochemistry (2002) 41:7907. doi:10.1021/bi025770x

20. Fisher CM. Pathological observations in hypertensive cerebral hemorrhage. JNeuropathol Exp Neurol (1971) 30:536-50. doi:10.1097/ 00005072-197107000-00015

21. Menon RS, Burgess RE, Wing JJ, Gibbons MC, Shara NM, Fernandez S, et al. Predictors of highly prevalent brain ischemia in intracerebral hemorrhage. Ann Neurol (2012) 71:199. doi:10.1002/ana.22668

22. Zazulia AR, Videen TO, Powers WJ. Transient focal increase in perihematomal glucose metabolism after acute human intracerebral hemorrhage. Stroke (2009) 40:1638. doi:10.1161/STROKEAHA.108.536037

23. Venkatasubramanian C, Mlynash M, Finley-Caulfield A, Eyngorn I, Kalimuthu R, Snider RW, et al. Natural history of perihematomal edema after intracerebral hemorrhage measured by serial magnetic resonance imaging. Stroke (2010) 42(1):73-80. doi:10.1161/STROKEAHA.110.590646

24. Ohwaki K, Yano E, Nagashima H, Hirata M, Nakagomi T, Tamura A. Blood pressure management in acute intracerebral hemorrhage: relationship between elevated blood pressure and hematoma enlargement. Stroke (2004) 35:1364. doi:10.1161/01.STR.0000128795.38283.4b

25. Sakamoto Y, Koga M, Yamagami H, Okuda S, Okada Y, Kimura K, et al. Systolic blood pressure after intravenous antihypertensive treatment and clinical outcomes in hyperacute intracerebral hemorrhage: the stroke acute management with urgent risk-factor assessment and improvement-intracerebral hemorrhage study. Stroke (2013) 44:1846. doi:10.1161/STROKEAHA.113.001212

26. Qureshi AI, Hanel RA, Kirmani JF, Yahia AM, Hopkins LN. Cerebral blood flow changes associated with intracerebral hemorrhage. Neurosurg Clin N Am (2002) 13(3):355-70. doi:10.1016/S1042-3680(02)00012-8

27. Powers WJ, Zazulia AR, Videen TO, Adams RE, Yundt KD, Aiyagari V, et al. Autoregulation of cerebral blood flow surrounding acute intracerebral hemorrhage. Neurology (2003) 57(1):18-24. doi:10.1212/WNL.57.1.18

28. Aksoy D, Bammer R, Mlynash M, Venkatasubramanian C, Eyngorn I, Snider RW, et al. Magnetic resonance imaging profile of blood-brain barrier injury in patients with acute intracerebral hemorrhage. J Am Heart Assoc (2013) 2:e000161. doi:10.1161/JAHA.113.000161

29. Kidwell CS, Burgess R, Menon R, Warach S, Latour LL. Hyperacute injury marker (HARM) in primary hemorrhage: a distinct form of CNS barrier disruption. Neurology (2011) 77:1725. doi:10.1212/WNL.0b013e318236ef46

30. Castillo J, Dávalos A, Alvarez-Sabín J, Pumar JM, Leira R, Silva Y, et al. Molecular signatures of brain injury after intracerebral hemorrhage. Neurology (2002) 58:624-9. doi:10.1212/WNL.58.4.624 Abilleira S, Montaner J, Molina CA, Monasterio J, Castillo J, Alvarez-Sabín J. Matrix metalloproteinase-9 concentration after spontaneous intracerebral hemorrhage. J Neurosurg 2003; 99:65-70. doi:10.3171/jns.2003.99.1.0065

31. Carhuapoma JR, Hanley DF, Banerjee M, Beauchamp NJ. Brain edema after human cerebral hemorrhage: a magnetic resonance imaging volumetric analysis. J Neurosurg Anesthesiol (2003) 15(3):230-3. doi:10.1097/ 00008506-200307000-00010

32. Qureshi AI, Palesch YY, Barsan WG, Hanley DF, Hsu CY, Martin RL, et al. Intensive blood-pressure lowering in patients with acute cerebral hemorrhage. N Engl J Med (2016) 375(11):1033-43. doi:10.1056/NEJMoa1603460

33. Garg RK, Liebling SM, Maas MB, Nemeth AJ, Russell EJ, Naidech AM. Blood pressure reduction, decreased diffusion on MRI, and outcomes after intracerebral hemorrhage. Stroke (2012) 43:67. doi:10.1161/STROKEAHA.111.629493

34. Butcher KS, Jeerakathil T, Hill M, Demchuk AM, Dowlatshahi D, Coutts SB, et al. The intracerebral hemorrhage acutely decreasing arterial pressure trial. Stroke (2013) 44:620. doi:10.1161/STROKEAHA.111.000188

35. Gould B, McCourt R, Asdaghi N, Dowlatshahi D, Jeerakathil T, Kate M, et al. Autoregulation of cerebral blood flow is preserved in primary intracerebral hemorrhage. Stroke (2013) 44:1726. doi:10.1161/STROKEAHA.113.001306

36. Anderson CS, Huang Y, Arima H, Heeley E, Skulina C, Parsons MW, et al. Effects of early intensive blood pressure-lowering treatment on the growth of hematoma and perihematomal edema in acute intracerebral hemorrhage: the intensive blood pressure reduction in acute cerebral haemorrhage trial (INTERACT). Stroke (2010) 41:307. doi:10.1161/STROKEAHA.109.561795

37. Anderson CS, Heeley E, Huang Y, Wang J, Stapf C, Delcourt C, et al. Rapid blood-pressure lowering in patients with acute intracerebral hemorrhage. $N$ Engl J Med (2013) 368:2355. doi:10.1056/NEJMoa1214609

38. Qureshi AI, Palesch YY, Martin R, Novitzke J, Cruz-Flores S, Ehtisham A, et al. Effect of systolic blood pressure reduction on hematoma expansion, perihematomal edema, and 3-month outcome among patients with intracerebral hemorrhage: results from the antihypertensive treatment of acute cerebral hemorrhage study. Arch Neurol (2010) 67:570. doi:10.1001/archneurol.2010.61

39. Baharoglu MI, Cordonnier C, Al-Shahi Salman R, de Gans K, Koopman MM, Brand A, et al. Platelet transfusion versus standard care after acute stroke due to spontaneous cerebral haemorrhage associated with antiplatelet therapy (PATCH): a randomised, open-label, phase 3 trial. Lancet (2016) 387(10038):2605-13. doi:10.1016/S0140-6736(16)30392-0

40. Mayer SA, Brun NC, Broderick J, Davis S, Diringer MN, Skolnick BE, et al. Safety and feasibility of recombinant factor VIIa for acute intracerebral hemorrhage. Stroke (2005) 36:74. doi:10.1161/01.STR.0000149628. 80251.b8

41. Mayer SA, Brun NC, Begtrup K, Broderick J, Davis S, Diringer MN, et al. Recombinant activated factor VII for acute intracerebral hemorrhage. $N$ Engl J Med (2005) 352:777. doi:10.1056/NEJMoa042991

42. Mayer SA, Brun NC, Begtrup K, Broderick J, Davis S, Diringer MN, et al. Efficacy and safety of recombinant activated factor VII for acute intracerebral hemorrhage. N Engl J Med (2008) 358:2127. doi:10.1056/ NEJMoa0707534

43. Diringer MN, Skolnick BE, Mayer SA, Steiner T, Davis SM, Brun NC, et al. Risk of thromboembolic events in controlled trials of rFVIIa in spontaneous intracerebral hemorrhage. Stroke (2008) 39:850. doi:10.1161/ STROKEAHA.107.493601

44. Morgenstern LB, Hemphill JC III, Anderson C, Becker K, Broderick JP, Connolly ES Jr, et al. Guidelines for the management of spontaneous intracerebral hemorrhage: a guideline for healthcare professionals from the American Heart Association/American Stroke Association. Stroke (2010) 41:2108. doi:10.1161/STR.0b013e3181ec611b

45. Hanley DF, Thompson RE, Muschelli J, Rosenblum M, McBee N, Lane K, et al. Safety and efficacy of minimally invasive surgery plus alteplase in intracerebral haemorrhage evacuation (MISTIE): a randomised, controlled, open-label, phase 2 trial. Lancet Neurol (2016) 15(12):1228-37. doi:10.1016/ S1474-4422(16)30234-4

46. Mendelow AD, Gregson BA, Fernandes HM, Murray GD, Teasdale GM, Hope DT, et al. Early surgery versus initial conservative treatment in patients with spontaneous supratentorial intracerebral haematomas in the International Surgical Trial in Intracerebral Haemorrhage (STICH): a randomised trial. Lancet (2005) 365:387. doi:10.1016/S0140-6736(05)70233-6

47. Mendelow AD, Gregson BA, Rowan EN, Murray GD, Gholkar A, Mitchell PM, et al. Early surgery versus initial conservative treatment in patients with spontaneous supratentorial lobar intracerebral haematomas (STICH II): a randomised trial. Lancet (2013) 382:397. doi:10.1016/S0140-6736(13)60986-1

48. Gautschi OP, Schaller K. Surgery or conservative therapy for cerebral haemorrhage? Lancet (2013) 382:377. doi:10.1016/S0140-6736(13)61087-9

49. Margetic S. Inflammation and haemostasis. Biochem Med (2012) 22(1):49-62. doi:10.11613/BM.2012.006

50. Vespa P, Hanley D, Betz J, Hoffer A, Engh J, Carter R, et al. ICES (intraoperative stereotactic computed tomography-guided endoscopic surgery) for brain hemorrhage: a multicenter randomized controlled trial. Stroke (2016) 47(11):2749-55. doi:10.1161/STROKEAHA.116.013837

Conflict of Interest Statement: The authors declare that the research was conducted in the absence of any commercial or financial relationships that could be construed as a potential conflict of interest.

Copyright $(2017$ Babi and James. This is an open-access article distributed under the terms of the Creative Commons Attribution License (CC BY). The use, distribution or reproduction in other forums is permitted, provided the original author $(s)$ or licensor are credited and that the original publication in this journal is cited, in accordance with accepted academic practice. No use, distribution or reproduction is permitted which does not comply with these terms. 